\title{
Application Research on Chinese History of Literature Language Medium
}

\author{
Yunjiang Wang \\ Arts and Sciences College, Yangling Vocational and Technical College, Shaanxi Yangling, 712100, \\ China
}

Keywords: Literature research, History of literature, Medium of language, Writers consciously

\begin{abstract}
This article is based on the history of the special form language media, from the perspective of the historical literature unique language form, its application in the history of literary creation is the concrete analysis, put forward in the historical literary creation process needs to be combined with actual situation selective use of history and modern languages, enriched the literary language media research history, for history literature creation provides scientific theoretical guidance, to help our country better development history of literature.
\end{abstract}

\section{Introduction}

Historical literary language system affected by history and literature duality properties, and has certain particularity; the main is that in order to make the literary form that can be accepted by the society in general. Historical literature should be used in the process of reflecting the historical life scenes "- a modern history" form of this form of language form, find the corresponding balance between old and this language, enhance the social adaptability of literature. At the same time, the creation of the writer in the history of literature also to the style of the text in the process of the subjects as well as the specific creation, aesthetic attitude and methods, the use of artistic language to grasp, and the application of the medium of language of literary history to the modern history of literature creation, improve the actual quality of modern literature.

\section{The unique form of history of literature language media}

In numerous literary criticism history study, language medium is a less even been completely ignored, "said" in the traditional language tools of thinking there is a connection, from language tools "speak" point of view, the study of language medium significantly less than its value on the reality of literature thought and exploration, language and media research has the certain difficulty, as a modern and narrates the ancient important media form and modeled after creation, easy to cause our country traditional historical research methods of literature study and theory has certain deficiency, even in the presence of different level, aphasia phenomenon.

Historical literary creation to depict and presentation of the history has become the past events, in accordance with the relevant theory reflects the basic principle and connotation, the artistic creation must be used to history of language form, avoid literary creation show the modernization of dense atmosphere. Even in a sense, the research community believes that only in the history of literature creation in the process of using the history of language to express the historical events can be classified as literary creation of respect The truth of history ${ }^{[1]}$. But, in the history of literature language media research process will be the claim in the context of research into the history and reality to carry on the deep review, will be able to find it has particularity and complexity. First of all, the history of pure literary language generally can't emersion. Authors use of material in the history of literary creation from the history books, but essentially, history and the history of the real and complete there exist certain differences between the account of the historical data by the spread of Chinese characters as well as the material conditions of constraints and privileged judgment on politics, culture, the influence of language in written symbol system and separation of special literature phenomenon, cause the history data cannot become the real language, the creation of modern social and historical literature produce some bad effects. Second, even if the creation of the 
writer in the history of literature is used in the history of literature language medium, but under the influence of modern education, generally only able to read the history of the language researchers, literary creation to lose its significance. In the process of actual research it is important to note that the study of language as a human civilization and special media forms and tools in the process of literary creation, in the development process of the general will be certain changes with the evolution of history. Some historical language symbol is A the name of the object, but after A long history of evolution may become an object, proposed an object or even not A name of the object. Language communication symbols dislocation in the process of historical evolution, metamorphosis etc. Phenomenon is relatively common problems. So, if the history of literature writers in order to pursue the truth of history and to compose, the spread of historical literature inevitably is a great deal of adverse effects. Hugo in the artistic creation cannot be absolute imitate the claim to the natural process through the analysis of the classic "XI DE" metaphor in the form of absurd paradox inference explains the historical literary language medium of history cannot be flattered, think history literature creation should not be in pursuit of the real reflection of history, but lost its literariness. But in the practice of the study is important to note that the history of literary creation language media cannot too pursuit of fully reflect the true history, and at the same time also should avoid to use pure Chinese, with a clear distinction of modern Chinese. Form of modern Chinese language media belongs to the category of modern literary language, its own language, voice, language rules and semantics with distinctive modern characteristics, and its artistic form of the time.

As is known to all, in the field of language research, language as a symbol of thinking message system, it is to reflect the ability of the object, and in essence it is the abstraction of the social reality of processing, is an important carrier of significance level. It is due to the characteristics of language, so the author in the process of creation of historical literature, in order to make the medium of language form to reflect the meaning of the object shown are history, make reflect the significance of the perceptual material form, cannot be directly using modern media language, especially in today's society is the value of directional strong language, such as the socialist economy, the core values, leasing, e-commerce, etc. In historical literature creation process to avoid this kind of language forms of media, but this kind of language has obvious directivity, make readers in the process of reading of history literature subconsciously linked with modern life, which in a sense of history is not adapt to the aesthetic aspect, affect readers' approval of literature ${ }^{[2]}$.

Based on the analysis of the above, historical literature language medium is neither purely modern language, not a single writings in classical style, but in the use of modern language according to the actual situation based on the basic form of the appropriate cut some modern idioms to evident, coupled with the historical characteristic of the literary language, eventually form historical literature unique language form, make its produce the function of the special effects.

\section{Historical analysis of application of literary language medium in the literary history}

"History- modern" the form is the historical literature language media form a basic formula of the system. In the process of specific literary creation, history literature language media application is more complex, not only lies in the language of the dislocation theory level, more important is the simpler form of theory into practice, aiming at specific problems will appear even more complex links and factors. The overall depends on the writer in the process of literary creation consciousness, only the history of literature writer in the process of creation consciously use medium of special language form, which can ensure the quality of the history of literature, and prompted the language medium forms play a important role.

First of all, the history of literature language medium the particularity and complexity of performance are in terms of stylistic differences. Due to historical literature and general literary form in the form of the style of specification there is a certain difference, so it should respect the differences in the specific application process, ensure the application effect. For historical novel creation in literature, the novel is the art of reading, the reader in the appreciation of this type of literary works can choose intensive reading and in the process of skimming, and whether it is a kind of reading form does not generally larger influence on the art of readers accept effect; And the 
comedy in the history of literature and film and television is a kind of used for on-the-spot ornamental art form, usually in the specific aspects presents "downstream straight down, moving" characteristics, on the forms of intuitive and continuity characteristics directly on the stage development history story, can deepen people understand the feeling of work and, this cannot stop the presentation and there was some difference of the novel. Li Yu once in view of the historical literature put forward its own views, think different forms of art in the history of literature, such as poems, lyrics, stops, and legendary creation has certain difference, so in the actual application process history literature language medium, need literati consciousness, the history of our country literary writer for the medium of language application and have had an impact. Therefore, in the specific creation practice, the writer should respect historical particularity and complexity of literary language media, in combination with different text form conscious attention to the language specification, it raises the artistic and cultural value of the history of literature.

Second, the practical application of history of literature language medium is affected by the works of narrative object. This article discusses the form of language is a kind of general, specific analysis in accordance with the relevant narrative theory, language can be divided into two narrative language and character language level. Narrative language is used by the author in literature language, generally used for environment description and express true feelings, tower, the research will be summarized as "meta-language" ${ }^{[3]}$. And the work of the character language is based on the story, given by the situation the self is not the author's words, but the works of the hero in a particular situation by using language. The character language description of narrative object is generally directly, and often lays out by means of dialogue, the tower, the image of the call "object" ${ }^{4]}$.These two important language is different to equivalent level sex, its essential function also has certain differences, so the writer in the using process of specific descriptions and characteristics should also show obvious differences. Mr. Zhang Xuecheng in study the authenticity of historical literature has been put forward in the process of the unique view, narrative language is considered the author can control, and even the author object language also can't control, the protagonist is a certain environment in their own personality must be driven by the spoken language, is not restricted by the authors subjective will. History of literary language media application, too, as the author of relevant historical narrative language practice, the author in the third person's identity to the readers about the events, while in the process of the specific application of coordination with language problems, but has great randomness, can be controlled by the author. Characters, language is not the case, the specific refers to the main characters in the works of the author to the reader in the history of tectonic environment, therefore, its normative stronger, not controlled by the author. For characters, language, history and literature creator though will not be able to let the spring and autumn period in the process of creation of historical task completely according to the time of the speech language specification, but must prevent modern directional strong words appear in the population, so the history of literature language media under the influence of object language should avoid modern characteristics, but should go through the corresponding language construct presents an historic thought.

Finally, history literature language medium concrete application is affected by the reader aesthetic value. Aesthetic value need writer to resolve the problem in the work show that the conscious mind, consciously reveal themselves through language attitude. In the process of the creation of the historical literature, the reappearance and expression, reality and romance, realism and lyrical in voice and tone shows the characteristics of certain differences. Among them, the former such as reproduction, practical and realistic language carrier contains a significant share of real perceptual and quality, basically can through social reality constitute a "homogeneous", the relationship between language form is relatively simple, and can avoid in the process of the actual creation of modern language creation tendency, makes every effort to literary works show the characteristics of ancient flavor, to ensure the reader to appreciate literary works could feel a part of the process to record the historical criticism and strange, text background for account of events and to the environment. The latter, such as performance, such as the romantic and lyric carrier is more obvious in the spiritual and emotional characteristics, its life and is the relationship between "heterogeneous" [5] Although narrative language also has the characteristics of the modeled, but overall is more passion, can bring 
the viewer strong impact on the vision. And its infiltration body feelings in his works, in terms of the proportion has been basically more than a statement of the event object. In the history of literature, the former is the typical representative of Tolstoy, Flaubert, such as Lu Xun, the outside, the latter is the typical representative of Shakespeare, Hugo, Guo Mo-ruo, his dragon interface, etc., they form the language medium in the creation of application showed the two types, and different types of aesthetic attitude there exist certain differences in the face of historical literature creation and appreciation of the corresponding influence.

\section{Conclusion}

To sum up, the creation of the historical literature needs to show its unique language form can truly specific historical and literary. So, based on the history of literature language medium in the form of a unique shape, applying historical literary language medium in the process of literature creation, should value the particularity and complexity of medium of language, and focus on the reader's aesthetic value and literature narrative object, reflect the history in as far as possible at the same time avoid the modern character of literary creation, enhance readers' identity of historical literature, thus to further promote the history of literature in the modern society, comprehensively promotes our country history of literature creation.

\section{References}

[1] Shen Ziqun. To the theory of language and the drive ensured regression - Han Dong for language, for literature renew, found again, and then explore. Suzhou university,2014.

[2] Long Qilin. Qing dynasty literary language comb spectrum and historical construction, evaluation of the division and construction: Qing dynasty literary language new study (1898-1917). Journal of Hubei institute for nationalities (philosophy and social sciences edition),2011,29(1):151-153.

[3] Shuang Xiuhai. The analysis of Tower language hierarchy. Journal of chongqing university of science and technology (social science edition) ,2014,28(2):18-23.

[4] Zheng Xinke. The penetration of literary consciousness in the junior middle school history classroom . Selective periodical of small writer,2015(26):151.

[5] Xing Juanni. Space-time open: literary language of social consciousness and Kim Chiu linguistics theory to explore the historical consciousness, Bach . Journal of Wenzhou university (social science edition),2014(4):35-38. 